\title{
Outcomes of endovascular thrombectomy in the elderly: a 'real-world' multicenter study
}

\author{
Ali Alawieh, ${ }^{1}$ Robert M Starke, ${ }^{2}$ Arindam Rano Chatterjee, ${ }^{3}$ Aquilla Turk, ${ }^{1}$ \\ Reade De Leacy, ${ }^{4}$ Ansaar T Rai, ${ }^{5}{ }^{5}$ Kyle Fargen, ${ }^{6}$ Peter Kan, ${ }^{7}$ Jasmeet Singh, ${ }^{6}$ \\ Lukas Vilella, ${ }^{6}$ Fábio A Nascimento, ${ }^{8}$ Travis M Dumont, ${ }^{9}$ David McCarthy, ${ }^{2}$ \\ Alejandro M Spiotta ${ }^{1}$
}

- Additional material is published online only. To view please visit the journal online (http://dx.doi.org/10.1136/ neurintsurg-2018-014289).

For numbered affiliations see end of article.

\section{Correspondence to}

Dr Alejandro M Spiotta, Division of Neurosurgery, Department of Neurosciences, Medical University of South Carolina, Charleston, SC 29425, USA; spiotta@musc.edu

Received 31 July 2018 Revised 26 September 2018 Accepted 2 October 2018 Published Online First

2 November 2018
Check for updates

(C) Author(s) (or their employer(s)) 2019. No commercial re-use. See rights and permissions. Published by BMJ.

To cite: Alawieh $A$ Starke RM, Chatterjee AR, et al. J Neurolntervent Surg 2019:11:545-553.

\section{ABSTRACT}

Background The efficacy of endovascular thrombectomy (ET) for acute ischemic stroke (AIS) in octogenarians is still controversial.

Objective To evaluate, using a large multicenter cohort of patients, outcomes after ET in octogenarians compared with younger patients.

Methods Data from prospectively maintained databases of patients undergoing ET for AIS at seven US-based comprehensive stroke centers between January 2013 and January 2018 were reviewed. Demographic, procedural, and outcome variables were collected. Outcomes included 90-day modified Rankin Scale (mRS) score, postprocedural National Institutes of Health Stroke Scale score, postprocedural hemorrhage, and mortality. Univariate and multivariate analyses were performed to assess the independent effect of age $\geq 80$ on outcome measures. Subgroup analyses were also performed based on location of stroke, success of recanalization, or ET technique used.

Results Rates of functional independence (mRS score $0-2$ ) after $\mathrm{ET}$ in elderly patients were significantly lower than for younger counterparts. Age $\geq 80$ was independently associated with increased mortality and poor outcome. Age $\geq 80$ showed an independent negative prognostic effect on outcome even when patients were divided according to thrombectomy technique, location of stroke, or success of recanalization. Age $\geq 80$ independently predicted higher rate of postprocedural hemorrhage, but not success of recanalization. Baseline deficit and number of reperfusion attempts, but not Thrombolysis in Cerebral Infarction score were associated with lower odds of good outcome.

Conclusion The large effect size of ET on AIS outcomes is significantly diminished in the elderly population when using comparable selection criteria to those used in younger counterparts. This raises concerns about the risk-benefit ratio and the cost-effectiveness of performing this procedure in the elderly before optimizing patient selection.

\section{INTRODUCTION}

Endovascular thrombectomy (ET) for acute ischemic stroke has been widely accepted as a firstline, standard of care intervention with level 1 evidence from multiple randomized controlled trials (RCTs). ${ }^{1-6}$ The large effect size of ET has led physicians and investigators to extend the eligibility for this intervention to patients who were not the focus of these randomized controlled trials. ${ }^{7-9}$ As a consequence, the current 'real-world' practice of ET in the United States today extends far beyond the narrow constraints of eligibility determined by the major RCTs and has included patients with low presenting National Institutes of Health Stroke Scale (NIHSS) score, low Alberta Stroke Program Early CT (ASPEC))T scores, posterior circulation infarcts, and elderly patients. ${ }^{9-22}$ As an ongoing quality assurance measure, it is thus imperative that we routinely monitor patient outcomes among cohorts for which there is no level 1 evidence to evaluate their candidacy for thrombectomy.

The case for ET in the elderly population (patients aged $\geq 80$ years), who were often excluded from, or under-represented, in RCTs, or for whom RCT data are not conclusive, is still controversial. ${ }^{923}$ This is an important area of investigation as the proportion of patients eligible for ET who are over the age of 80 is increasing. Many conclusions about the efficacy and safety of ET in the elderly have been reached based on single-arm, single-institution studies with significant heterogeneity across studies, ${ }^{9-14}$ 17-20 23-25 often without comparison with optimal medical management. Previous single-institution, retrospective evaluations of elderly patients presenting with acute stroke demonstrated no additional benefit of ET using aspiration at first pass compared with matched controls receiving optimal medical management. Furthermore, the ET group had a higher rate of mortality and hemorrhage. $^{9}$ In this multicenter expansion of prior work, we selected one of the largest datasets of patient outcomes after level 1 evidence backed ET approaches (aspiration and stent retriever) in 'realworld' practice across multiple centers to evaluate thrombectomy outcomes in octogenarians. We also evaluated the associations between advanced age and negative outcomes across different anatomic and technical subgroups.

\section{METHODS}

Seven US-based comprehensive stroke centers independently maintained prospectively collected databases of consecutive patients treated with ET for acute ischemic stroke with large vessel occlusion between January 2013 and December 2017. Patients aged $\geq 18$ years with anterior or posterior 
circulation stroke were included, irrespective of time from onset to groin, NIHSS score at presentation, or whether IV tissue plasminogen activator (tPA) was administered. Patients treated with stent retriever or aspiration thrombectomy as first approach were included. De-identified data from all sites were collected, organized, and analyzed at the Medical University of South Carolina with approval of the institutional review board at each site.

\section{Data collection}

Patient charts and procedure notes were reviewed for demographics, preprocedural deficit, and the procedural variables. Patient charts were also reviewed for comorbidities including, hypertension, hyperlipidemia, atrial fibrillation, and diabetes. Procedural variables collected for each patient included the time to achieve recanalization (procedure time), IA tPA administration, the number of vessels/branches subjected to thrombectomy, the aspiration, and at the end of procedure, intraprocedural complications, the number of devices used, the number of passes including aspiration and other devices. Procedural outcome included reperfusion classification using the Thrombolysis in Cerebral Infarction (TICI) score and postprocedural hemorrhage using the European Cooperative Acute Stroke Study (ECASS) radiological classification of hemorrhagic infarcts (HI1 and $\mathrm{HI} 2$ ), parenchymal hematomas (PH1 and $\mathrm{PH} 2)$, and subarachnoid hemorrhage. ${ }^{26}$

\section{Clinical outcomes}

The modified Rankin Scale (mRS) score at 90 days was used as the primary clinical outcome and was dichotomized into good outcome (mRS score 0-2) and poor outcome (mRS score 3-6). Length of hospitalization was also recorded. The 90-day mRS scores were recorded by a stroke neurologist during follow-up visits at 90 days $( \pm 14)$ after stroke or via telephone encounters with rehabilitation facilities or nursing homes for patients in a hospice or who had died during this interval. Mortality data were collected using follow-up calls, death certificates, or communication with nursing facilities.

\section{Statistical analysis}

Statistical analyses were performed using SPSS v24 (IBM Corporation, New York, USA) and Graphpad Prism 6 (Graphpad, La Jolla, California, USA). Descriptive statistics and univariate comparisons were used. Comparisons were performed using the Student's t test or analysis of variance with Bonferroni's multiple comparisons for continuous measures, non-parametric $t$ test or Mann-Whitney test with Dunn's multiple comparisons for non-continuous variables, and a $\chi^{2}$ test with likelihood ratios for categorical measures. All tests were two-sided and an $\alpha$ value $<0.05$ was considered significant. Three baseline variablesnamely, race, onset-to-groin time, and baseline mRS-were not available for $15 \%$ of the patients, and were interpolated to avoid exclusion of data on multivariate analysis. Several machine learning classifiers were used for data interpolation using WEKA (University of Waikato), as described below.

A panel of machine learning appropriate for each variable was implemented on a training set of $85 \%$ of the patients, including all demographic and procedural features without outcomes, followed by 10 -fold cross validation. The best performing model was chosen for interpolation of the remaining $15 \%$ of patients. Interpolation was performed when one or two of the four variables were missing. The models used were J48-decision trees for race (area under the curve: 0.7), REP-Tree algorithm for onset-to-groin (mean absolute error: 2 hours), meta-vote classifier for baseline mRS (mean absolute error: 0.15), and M5-rules for admission NIHSS score (mean absolute error: 4). Multivariate logistic regression analyses were used for predictors of good outcome and mortality (two independent models), and included patients with a complete dataset. All multivariate models were assessed using the Hosmer-Lemeshow test and c-statistics. Variables were included in models based on statistical significance on univariate analysis and/or clinical relevance.

\section{RESULTS}

\section{Patient cohort characteristics and outcomes}

A total of 1442 patients who matched the inclusion criteria were enrolled during the study period. Of these patients, 96 were excluded because of missing more than two baseline or demographic characteristics or missing procedural data. Univariate analysis was performed on the remaining 1346 patients.

The mean age of included patients was $68 \pm 15$ years, of whom $52 \%$ were women and $62 \%$ were white. The average symptom onset-to-groin time was 400 with SD of $517 \mathrm{~min}$, the mean NIHSS score at presentation was $16.5 \pm 7$, and the median $\mathrm{mRS}$ before stroke was 0 (IQR 1). Posterior circulation strokes were treated in $12 \%$ of patients. Treatment with IV tPA was provided to $45.5 \%$ of all patients. Aspiration catheters were used at first pass (ADAPT) in 58\% of patients; the remainder underwent stent retriever thrombectomy as first-line therapy. Postprocedural reperfusion with TICI $\geq 2 \mathrm{~b}$ was reported in $89 \%$ of cases, a good outcome (mRS score 0-2) was observed in $37.5 \%$ of the cases at 90 days, and the overall mortality at 90 days was $24.4 \%$. The overall rate of postprocedural hemorrhage was $31 \%$, and the rate of $\mathrm{PH} 2$-type hemorrhage was $4.4 \%$.

\section{Patient features and outcomes for each age group}

When functional outcomes were stratified by age group, an age-dependent decrease in rates of functional independence and increased likelihood of higher mRS scores with age was observed (figure 1A). The rates of good and poor outcomes are nearly comparable between 40 and 75 years of age, followed by a cumulative increase of likelihood of poor outcomes (figure 1B) and mortality (figure 1C) after 80 years of age. The receiver operating characteristic curve correlating age and likelihood of good outcomes showed optimal sensitivity and specificity trade-off at 80 years of age, and a similar pattern was observed when correlating age at presentation and likelihood of mortality (figure 1D,E). Based on these data, and prior findings reporting higher rates of poor outcomes in the elderly, patients were dichotomized by age using 80 years as the cut-off point, and the elderly were defined as those aged $\geq 80$ years at presentation.

The average age in elderly group was $85 \pm 5$ years compared with $62 \pm 13$ years in the younger population. Univariate analysis showed a significantly higher percentage of women in the elderly group (66\% vs 47\%, p<0.01), without significant difference in the distribution by race, time from onset to groin, or history of prior stroke between the two groups (table 1). Elderly patients had a significantly higher number of comorbidities than the younger group, including hypertension and atrial fibrillation. There was no significant difference in history of prior stroke between the two groups, but a slightly higher NIHSS score on admission was found in the elderly population compared with younger adults $(17 \pm 7$ vs $16 \pm 7, \mathrm{p}<0.01)$ (table 1$)$. There was no significant difference in the rates of posterior circulation strokes or use of IV tPA between the two groups (table 1). Patients in the elderly population had slightly higher ASPECT scores (median 
A

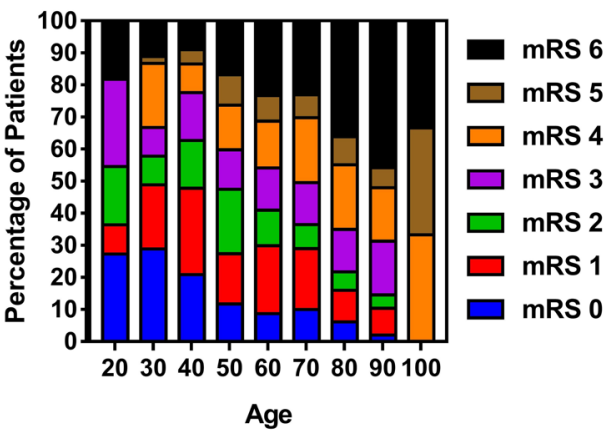

B

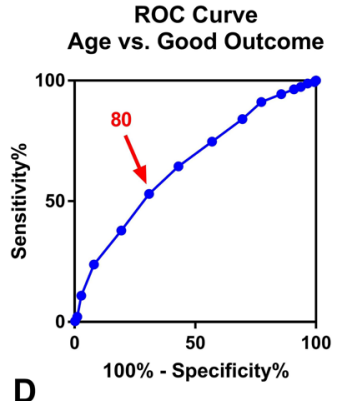

Rates of Good/Bad Outcome by Age Group

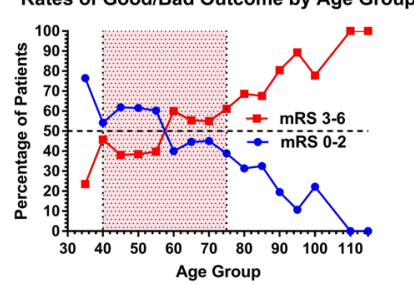

C
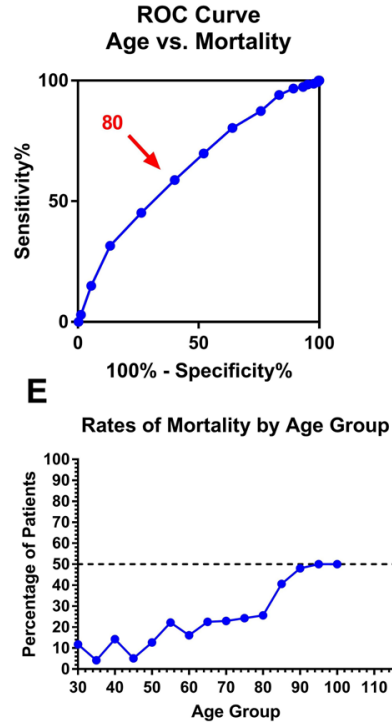

Figure 1 Outcomes after endovascular thrombectomy by age groups. (A) Distribution of 90-day modified Rankin Scale (mRS) scores by age groups. (B) Receiver operating characteristic (ROC) curve demonstrating the specificity and sensitivity of age as a predictor of good outcome at 90 days. An age of 80 (75-85) denotes the optimal sensitivity - specificity trade-off of the curve. (C) Similar to (B) when age is used as a predictor of 90 - day mortality. (D) Distribution of rates of good outcome (mRS score 0-2, blue) and poor outcome (mRS score 3-6) by age groups. (E) Rate of mortality by different age groups.

9 vs $8, p<0.01)$ compared with the younger adults, which was statistically significant (table 1 ).

\section{Procedural endpoints, outcomes, and age}

No significant differences between the elderly and younger patients were found for the majority of procedural variables, including procedure time, use of IA tPA, use of aspiration at first pass, use of stent retrievers or alternative devices, final TICI scores, or complication rates (table 1). A significantly lower total number of attempts was used in the elderly patients compared with younger adults, and a smaller percentage of patients in the elderly group received more than three reperfusion attempts $(32 \%$ vs $39 \%, p<0.05)$ (table 1$)$. However, the rate of successful TICI $2 b$ or greater recanalization was comparable between the two groups $(p>0.05)$. The rate of postprocedural hemorrhage was significantly higher in the elderly patients than in the younger adults $(42 \%$ vs $28 \%, \mathrm{p}<0.01)$, but there was no significant difference in the rate of $\mathrm{PH} 2$-type hemorrhage (7\% vs $4 \%$, $\mathrm{p}=0.07)$ (table 1).

For clinical outcomes, the median mRS score at 90 days was 4 in the elderly group compared with 3 in younger adults, and the rates of good outcomes (mRS score $0-2)$ were $21 \%$ compared with $44 \%$, respectively $(\mathrm{p}<0.001)$ (table 1$)$. Similarly, the mortality rate at 90 days was significantly higher in the elderly population than in younger adults $(35 \%$ vs $20 \%, \mathrm{p}<0.001)$ (table 1). Elderly patients had higher NIHSS at discharge and a smaller improvement in NIHSS score between admission and discharge compared with younger counterparts $(\mathrm{p}<0.01$, table 1). There was no difference in the length of hospital stay between the two groups.

\section{Predictors of outcome and mortality}

We then used multivariate logistic regression to determine whether an age of $\geq 80$ is an independent predictor of outcome and mortality at 90 days. For multivariate regression analysis, patients missing outcome or procedural variables were excluded $(\mathrm{n}=120)$, and 1226 patients were included in the multivariate models. As shown in table 2 , age $\geq 80$ was associated with significantly decreased odds of good outcome $(\mathrm{OR}=0.4, \mathrm{p}<0.001)$, and higher odds of mortality at 90 days $(\mathrm{OR}=2.23, \mathrm{p}<0.001)$ (table 2). Additional significant predictors of poor outcome and mortality were higher baseline mRS score, higher admission NIHSS score, location in posterior circulation, higher number of attempts to recanalization, and lower TICI scores after the procedure (table 2). Female gender was associated with lower odds of good outcome $(\mathrm{OR}=0.66, \mathrm{p}<0.01)$, and complications were associated with higher odds of mortality at 90 days $(\mathrm{OR}=1.97, \mathrm{p}<0.05)$ (table 2$)$. Age $\geq 80$ was consistently associated with lower odds of good outcome on multivariate analysis when good outcome was defined as an mRS score of $0-1$ at 90 days $(\mathrm{OR}=0.47, \mathrm{p}<0.001)$ (online supplementary table 1$)$.

\section{Subgroup analysis for outcome predictors}

To determine if a specific clinical subset of patients was associated with a higher risk of poor outcome, we performed multivariate regression analysis to predict an mRS score of a $0-2$ at 90 days when patients were divided according to stroke location, aspiration techniques, or extent of recanalization (TICI score).

When stratified by location (anterior or posterior circulation stroke), age at presentation of $\geq 80$ was associated with lower odds of good outcomes in both anterior circulation $(\mathrm{OR}=0.35, \mathrm{p}<0.001)$ and posterior circulation $(\mathrm{OR}=0.23$, $\mathrm{P}=0.039$ ) (table 3 ). Since ASPECT scores were available only for a subset of patients in the anterior circulation group, analysis was performed independently on these subjects while incorporating ASPECT scores (online supplementary table 2). Results confirm those shown in table 3, and also emphasize ASPECT scores as independent predictors of good outcome. Stratification by the initial thrombectomy approach (aspiration or stent retriever) also showed that age at presentation of $\geq 80$ was associated with lower odds of good outcomes in patients treated with aspiration $(\mathrm{OR}=0.4, \mathrm{p}<0.001)$ or stent retriever $(\mathrm{OR}=0.43, \mathrm{p}<0.001)$ thrombectomy at first pass (table 4). Patients were then stratified based on TICI scores into TICI $2 b$ or TICI $2 \mathrm{c} / 3$, and similar multivariate regression analysis was performed to predict good outcomes (table 5). An age of $\geq 80$ years was also associated with lower odds of good outcome in patients with TICI $2 \mathrm{c} / 3(\mathrm{OR}=0.43, \mathrm{p}<0.001)$ and patients with TICI $2 \mathrm{~b}(\mathrm{OR}=0.43, \mathrm{p}<0.001)$ independently (table 5$)$. Notably, age $\geq 80$ was not an independent predictor for complete recanalization after ET on multivariate analysis, confirming the findings on univariate analysis $(p=0.709)$ (online supplementary table 3). Similarly, elderly patients had a significantly higher odds of 
Ischemic Stroke

Table 1 Comparison of baseline characteristics, procedural and outcome measures in patients aged $<80$ years and those aged $\geq 80$ years

\begin{tabular}{|c|c|c|c|c|c|}
\hline \multirow[b]{2}{*}{ Variable } & \multirow[b]{2}{*}{$\mathrm{N}$} & \multirow{2}{*}{$\begin{array}{l}\text { Age } \\
<80 \\
(n=1000)\end{array}$} & \multirow{2}{*}{$\begin{array}{l}\text { Age } \\
\geq 80 \\
(n=346)\end{array}$} & \multirow[b]{2}{*}{ Test used } & \multirow[b]{2}{*}{ Test summary } \\
\hline & & & & & \\
\hline \multicolumn{6}{|l|}{ Preprocedure } \\
\hline Age (years) & 1346 & $62(13)$ & $85(5)$ & $\mathrm{t}$ Test & $<0.001$ \\
\hline Female (n (\%)) & 1346 & $474(47)$ & $230(66)$ & $\chi^{2}$ & $<0.01$ \\
\hline White $(\mathrm{n}(\%))$ & 1346 & $666(67)$ & $240(69)$ & $\chi^{2}$ & $>0.05$ \\
\hline Pre-stroke mRS score (median (IQR)) & 1346 & $0(1)$ & $0(1)$ & MW & $>0.05$ \\
\hline Baseline NIHSS score & 1346 & $16(7)$ & $17(7)$ & $\mathrm{t}$ Test & $<0.01$ \\
\hline Time from onset to groin (hours) & 1346 & 399 (402) & $369(527)$ & $\mathrm{t}$ Test & $>0.05$ \\
\hline IV tPA $(n(\%))$ & 1346 & $445(45)$ & $168(49)$ & $\chi^{2}$ & $>0.05$ \\
\hline Number of comorbidities*(median (IQR)) & 1224 & $2(1)$ & $2(2)$ & MW & $<0.05$ \\
\hline Diabetes mellitus ( $(\%))$ & 1224 & $243(27)$ & $73(23)$ & $\chi^{2}$ & $>0.05$ \\
\hline Hypertension (n (\%)) & 1224 & $575(63)$ & $229(73)$ & $\chi^{2}$ & $<0.05$ \\
\hline Atrial fibrillation ( $\mathrm{n}(\%))$ & 1224 & $241(27)$ & $119(38)$ & $\chi^{2}$ & $<0.05$ \\
\hline Hyperlipidemia (n (\%)) & 1224 & $301(33)$ & $120(38)$ & $\chi^{2}$ & $>0.05$ \\
\hline Prior stroke & 1346 & $59(6)$ & $28(8)$ & $\chi^{2}$ & $>0.05$ \\
\hline \multicolumn{6}{|l|}{ Location } \\
\hline Anterior circulation (n (\%)) & 1346 & $870(87)$ & $310(90)$ & $\chi^{2}$ & $>0.05$ \\
\hline Vessel involved (n (\%)) & 1334 & & & $\chi^{2}$ & $>0.05$ \\
\hline ICA & & $144(15)$ & $50(15)$ & & \\
\hline Tandem & & $31(3)$ & $13(4)$ & & \\
\hline M1 & & $495(50)$ & $182(53)$ & & \\
\hline M2 & & $156(16)$ & $55(16)$ & & \\
\hline M3 & & $25(3)$ & $9(3)$ & & \\
\hline Basilar & & $106(11)$ & $21(6)$ & & \\
\hline Othert & & $36(4)$ & $11(3)$ & & \\
\hline ASPECT score (median (IQR)) & 875 & $8(2)$ & $9(3)$ & MW & $<0.01$ \\
\hline \multicolumn{6}{|l|}{ Procedure } \\
\hline Time to recanalization (min) & 1022 & $48(41)$ & $45(33)$ & $\mathrm{t}$ Test & $>0.05$ \\
\hline IA tPA $(n(\%))$ & 1298 & $155(16)$ & $53(16)$ & $\chi^{2}$ & $>0.05$ \\
\hline Aspiration at first pass $(\mathrm{n}(\%))$ & 1336 & $592(59)$ & $188(55)$ & $\chi^{2}$ & $>0.05$ \\
\hline Use of stent retrievers $(n(\%))$ & 1336 & $531(53)$ & $191(56)$ & $\chi^{2}$ & $>0.05$ \\
\hline Use of additional devices $¥(\mathrm{n}(\%))$ & 1336 & $131(13)$ & $36(10)$ & $\chi^{2}$ & $>0.05$ \\
\hline Number of passes (Mean (Median)) & 1299 & $2.5(2)$ & $2.3(2)$ & MW & $<0.05$ \\
\hline Number of passes ( $(\%))$ & 1299 & & & $\chi^{2}$ & $<0.05$ \\
\hline$<3$ & & $590(61)$ & $227(68)$ & & \\
\hline$\geq 3$ & & $375(39)$ & $107(32)$ & & \\
\hline Final TICl score (n (\%)) & 1346 & & & $\chi^{2}$ & $>0.05$ \\
\hline $2 b-3$ & & $884(88)$ & $304(88)$ & & \\
\hline $0-2 a$ & & $116(12)$ & $42(12)$ & & \\
\hline $\mathrm{TICl}$ score $2 \mathrm{C}-3(\mathrm{n}(\%))$ & 1346 & $404(40)$ & $130(38)$ & $\chi^{2}$ & $>0.05$ \\
\hline Complications ( $(\%))$ & 1346 & $50(5)$ & $15(4)$ & $\chi^{2}$ & $>0.05$ \\
\hline Hemorrhage, all types ( $\mathrm{n}(\%))$ & 1101 & $251(28)$ & $93(42)$ & $\chi^{2}$ & $<0.01$ \\
\hline Hemorrhage, $\mathrm{PH} 2$ & 1101 & $33(4)$ & $15(7)$ & $\chi^{2}$ & 0.07 \\
\hline \multicolumn{6}{|l|}{ Outcome (90 day) } \\
\hline mRS (median (IQR)) & 1226 & $3(4)$ & $4(3)$ & MW & $<0.001$ \\
\hline mRS dichotomized (n (\%)) & 1226 & & & $\chi^{2}$ & $<0.001$ \\
\hline mRS score $0-2$ & & $398(44)$ & $65(21)$ & & \\
\hline
\end{tabular}


Table 1 Continued

\begin{tabular}{|c|c|c|c|c|c|}
\hline & & Age & Age & & \\
\hline Variable & $\mathrm{N}$ & $\begin{array}{l}<80 \\
(n=1000)\end{array}$ & $\begin{array}{l}\geq 80 \\
(n=346)\end{array}$ & Test used & Test summary \\
\hline $\mathrm{mRS}$ score $>2$ & & $515(56)$ & $247(79)$ & & \\
\hline Death (n (\%)) & 1226 & $184(20)$ & $118(38)$ & $\chi^{2}$ & $<0.001$ \\
\hline NIHSS at discharge & 919 & $8.3(10)$ & $13(12)$ & t Test & $<0.001$ \\
\hline$\triangle$ NIHSS (discharge-admission) & 919 & $-7.5(10)$ & $-4(12)$ & t Test & $<0.01$ \\
\hline Length of hospitalization (days) & 1094 & $11(12)$ & $10(11)$ & t Test & $>0.05$ \\
\hline
\end{tabular}

Values are $\mathrm{n}(\%)$ or mean (SD) or median (IQR).

$\chi^{2}$ Test for categorical variables, Student's t test was used for parametric variables, or the Mann-Whitney test for non-parametric variables.

*Number of comorbidities includes the number of comorbidities (hypertension, hyperlipidemia, diabetes, atrial fibrillation) present in each patient and ranges from 0 to 4.

tOther vessels include posterior cerebral artery, anterior cerebral artery, and vertebral arteries.

¥0ther devices include reperfusion catheters, Penumbra separators, embolic protectors, and others.

ICA, internal carotid artery; mRS, modified Rankin Scale; MW, Mann-Whitney test; NIHSS, National Institutes of Health Stroke Scale; PH2, parenchymal hematoma 2; TICI,

Thrombolysis in Cerebral Infarction; tPA, tissue plasminogen activator.

postprocedural hemorrhage than younger patients $(\mathrm{OR}=1.59$, $\mathrm{p}<0.01$ ) (table 6).

\section{Predictors of good outcome in each group}

Finally, we assessed whether different variables predict outcomes after ET in elderly patients compared with younger adults using multivariate logistic regression. As shown in table 7, higher baseline and pre-stroke deficits as well as higher number of recanalization attempts were associated with lower odds of good outcome in the two groups; however, posterior circulation strokes were associated with lower odds of good outcome in the young population $(\mathrm{OR}=0.35, \mathrm{p}<0.001)$ compared with higher odds of good outcome in the elderly $(\mathrm{OR}=3.43, \mathrm{p}<0.05)$. Male gender was associated with increased odds of good outcome in younger adults, but not in elderly patients (table 7). When TICI scores were analyzed as an ordinal variable, increasing TICI scores were associated with higher odds of good outcomes in younger adults, but not in octogenarians.

\section{DISCUSSION}

This multicenter study recapitulated previous single-center studies describing low rates of functional independence after ET in elderly patients compared with younger counterparts. This study suggests an age of $\geq 80$ years is associated with increased mortality and poor outcome rates despite comparable baseline and procedural variables. Additionally, age of $\geq 80$ was found to be an independent predictor of poor outcome (mRS score 2-6) and mortality after thrombectomy at multiple centers. The negative prognostic effect of octogenarian age persisted when patients were split by thrombectomy technique (aspiration vs stent retriever), location of stroke (posterior vs anterior circulation), or by success of recanalization. We also demonstrate that an age of $\geq 80$ years is not an independent predictor of recanalization success, but independently predicts a higher rate of postprocedural hemorrhage. This discrepancy in response to ET between the two distinct age groups raises concerns about the risk-benefit ratio and the cost-effectiveness of performing

Table 2 Multivariate analysis for predictors of good outcome and mortality at 90 days after endovascular thrombectomy

\begin{tabular}{|c|c|c|c|c|c|c|}
\hline \multirow[b]{2}{*}{ Variable } & \multicolumn{3}{|c|}{ Multivariate model for good outcome $(n=1226)$} & \multicolumn{3}{|c|}{ Multivariate model for mortality $(n=1226)$} \\
\hline & OR & $95 \% \mathrm{Cl}$ & $P$ values & OR & $95 \% \mathrm{Cl}$ & $P$ values \\
\hline Female gender & 0.66 & 0.58 to 0.75 & 0.003 & 0.95 & 0.82 to 1.1 & 0.752 \\
\hline White & 0.97 & 0.84 to 1.11 & 0.814 & 1.85 & 1.56 to 2.19 & 0.001 \\
\hline Age $\geq 80$ & 0.40 & 0.34 to 0.47 & $<0.001$ & 2.23 & 1.9 to 2.61 & $<0.001$ \\
\hline Onset to groin time & 1.00 & 1 to 1 & 0.525 & 1.00 & 1 to 1 & 0.31 \\
\hline Pre-stroke mRS score & 0.75 & 0.7 to 0.8 & $<0.001$ & 1.29 & 1.22 to 1.36 & $<0.001$ \\
\hline Baseline NIHSS score & 0.90 & 0.89 to 0.91 & $<0.001$ & 1.09 & 1.08 to 1.1 & $<0.001$ \\
\hline Number of comorbidities & 0.95 & 0.89 to 1 & 0.319 & 1.08 & 1.02 to 1.15 & 0.225 \\
\hline Posterior circulation stroke & 0.48 & 0.38 to 0.59 & 0.001 & 2.14 & 1.74 to 2.64 & $<0.001$ \\
\hline Prior stroke & 1.14 & 0.87 to 1.49 & 0.639 & 0.53 & 0.39 to 0.73 & 0.062 \\
\hline IV tPA & 1.13 & 0.99 to 1.3 & 0.395 & 0.77 & 0.66 to 0.89 & 0.092 \\
\hline IA tPA & 0.87 & 0.73 to 1.04 & 0.471 & 0.99 & 0.82 to 1.2 & 0.967 \\
\hline Number of attempts & 0.84 & 0.8 to 0.87 & $<0.001$ & 0.88 & 0.85 to 0.92 & 0.004 \\
\hline Use of aspiration at first pass & 0.90 & 0.78 to 1.05 & 0.519 & 0.83 & 0.71 to 0.97 & 0.248 \\
\hline $\mathrm{TICl}$ score & 1.24 & 1.17 to 1.31 & $<0.001$ & 1.14 & 1.07 to 1.21 & 0.038 \\
\hline Complications & 0.55 & 0.39 to 0.77 & 0.09 & 1.97 & 1.46 to 2.67 & 0.032 \\
\hline
\end{tabular}

Variables showing statistical significance $(p<0.05)$ are in bold.

mRS, modified Rankin Scale; NIHSS, National Institutes of Health Stroke Scale; tPA, tissue plasminogen activator. 
Ischemic Stroke

Table 3 Multivariate analysis for predictors of good outcome at 90 days after endovascular thrombectomy by location

\begin{tabular}{|c|c|c|c|c|c|c|}
\hline \multirow[b]{2}{*}{ Variable } & \multicolumn{3}{|c|}{ Multivariate - anterior circulation $(n=1033)$} & \multicolumn{3}{|c|}{ Multivariate - posterior circulation $(n=144)$} \\
\hline & OR & $95 \% \mathrm{Cl}$ & $P$ values & OR & $95 \% \mathrm{Cl}$ & $P$ values \\
\hline Female gender & 0.64 & 0.48 to 0.86 & 0.003 & 0.88 & 0.34 to 2.29 & 0.792 \\
\hline White & 0.94 & 0.69 to 1.28 & 0.700 & 1.30 & 0.44 to 3.88 & 0.637 \\
\hline Age $\geq 80$ & 0.35 & 0.24 to 0.5 & $<0.001$ & 0.23 & 0.06 to 0.93 & 0.039 \\
\hline Onset-to-groin time & 1.00 & 1 to 1 & 0.928 & 1.00 & 1 to 1 & 0.162 \\
\hline Pre-stroke mRS & 0.70 & 0.6 to 0.82 & $<0.001$ & 1.59 & 1.03 to 2.44 & 0.050 \\
\hline Baseline NIHSS & 0.90 & 0.88 to 0.92 & $<0.001$ & 0.88 & 0.83 to 0.93 & $<0.001$ \\
\hline Number of comorbidities & 0.96 & 0.85 to 1.08 & 0.525 & 0.66 & 0.43 to 1.02 & 0.064 \\
\hline Prior stroke & 1.03 & 0.58 to 1.84 & 0.919 & 1.04 & 0.14 to 7.74 & 0.968 \\
\hline IV tPA & 1.13 & 0.84 to 1.52 & 0.438 & 1.36 & 0.44 to 4.14 & 0.594 \\
\hline IA tPA & 0.92 & 0.62 to 1.36 & 0.683 & 1.18 & 0.31 to 4.41 & 0.811 \\
\hline Number of attempts & 0.82 & 0.75 to 0.9 & $<0.001$ & 0.93 & 0.7 to 1.23 & 0.596 \\
\hline TICI Score & 1.21 & 1.07 to 1.37 & 0.002 & 2.11 & 1.3 to 3.41 & 0.002 \\
\hline Complications & 0.58 & 0.28 to 1.23 & 0.156 & 19.05 & 1.1 to 32 & 0.043 \\
\hline
\end{tabular}

Variables showing statistical significance $(p<0.05)$ are in bold.

mRS, modified Rankin Scale; NIHSS, National Institutes of Health Stroke Scale; TICl, Thrombolysis in Cerebral Infarction; tPA, tissue plasminogen activator.

Table 4 Multivariate analysis for predictors of good outcome at 90 days after endovascular thrombectomy by initial technique

\begin{tabular}{|c|c|c|c|c|c|c|}
\hline \multirow[b]{2}{*}{ Variable } & \multicolumn{3}{|c|}{ Multivariate - stent retriever $(n=444)$} & \multicolumn{3}{|c|}{ Multivariate - aspiration $(n=734)$} \\
\hline & $\mathrm{OR}$ & $95 \% \mathrm{Cl}$ & $P$ values & OR & $95 \% \mathrm{Cl}$ & $P$ values \\
\hline Female gender & 0.62 & 0.4 to 0.97 & 0.037 & 0.68 & 0.48 to 0.97 & 0.031 \\
\hline White & 1.52 & 0.84 to 2.73 & 0.162 & 0.84 & 0.59 to 1.2 & 0.332 \\
\hline Age $\geq 80$ & 0.40 & 0.24 to 0.68 & $<0.001$ & 0.43 & 0.27 to 0.69 & $<0.001$ \\
\hline Onset-to-groin time & 1.00 & 1 to 1 & 0.428 & 1.00 & 1 to 1 & 0.625 \\
\hline Pre-stroke mRS & 0.82 & 0.67 to 1.01 & 0.059 & 0.70 & 0.57 to 0.86 & 0.001 \\
\hline Baseline NIHSS & 0.91 & 0.88 to 0.94 & $<0.001$ & 0.89 & 0.87 to 0.92 & $<0.001$ \\
\hline Posterior circulation stroke & 0.29 & 0.14 to 0.61 & 0.001 & 0.66 & 0.36 to 1.21 & 0.181 \\
\hline Number of comorbidities & 0.93 & 0.77 to 1.11 & 0.398 & 0.93 & 0.8 to 1.08 & 0.351 \\
\hline IV tPA & 1.30 & 0.81 to 2.1 & 0.278 & 0.97 & 0.68 to 1.4 & 0.885 \\
\hline IA tPA & 0.75 & 0.42 to 1.35 & 0.336 & 1.07 & 0.65 to 1.76 & 0.788 \\
\hline Number of attempts & 0.86 & 0.73 to 1.02 & 0.092 & 0.83 & 0.75 to 0.93 & 0.001 \\
\hline $\mathrm{TICl}$ score & 1.05 & 0.86 to 1.29 & 0.608 & 1.35 & 1.16 to 1.57 & $<0.001$ \\
\hline Complications & 0.48 & 0.17 to 1.36 & 0.167 & 0.58 & 0.22 to 1.52 & 0.265 \\
\hline
\end{tabular}

Variables showing statistical significance $(p<0.05)$ are in bold.

mRS, modified Rankin Scale; NIHSS, National Institutes of Health Stroke Scale; TICl, Thrombolysis in Cerebral Infarction; tPA, tissue plasminogen activator.

this procedure in the elderly using comparable selection criteria to those used for younger counterparts. Practitioners should be aware that the large treatment effect is significantly mitigated in the elderly population.

Previous work on the impact of age on outcomes after thrombectomy have consistently shown that age is an independent predictor of functional independence and mortality at 90 days after ET. ${ }^{9}{ }^{152-30}$ Subsequent studies evaluated the rate of change in rates of functional independence after ET with age, and a cut-off point of 80 years of age that was used as the upper limit in the RCTs was described as the point beyond which there is a rapid decline in rates of good outcomes after ET. ${ }^{9202324}$

We have confirmed, in this multicenter study, the rapid age-dependent increase in mortality rate and rate of poor outcomes after ET in octogenarians. The reduced efficacy of ET in octogenarians compared with younger counterparts has been also confirmed by prior studies, ${ }^{173132}$ which demonstrated questionable efficacy and/or higher complication rates and mortality in octogenarians after ET. However, several reports argue that despite the reduced efficacy of ET in octogenarians, they still have significant rates of functional independence after ET. ${ }^{17202324}$ A major limitation of these studies is the small sample size and the comparison of elderly patients with trial patients or historic controls. ${ }^{9} 1317182023-25$

The discrepancy in reported outcomes has been recently emphasized in a meta-analysis by Hilditch $e t a l^{23}$ of prospective and retrospective data from 860 patients. The study noted significant heterogeneity between published reports, with $\mathrm{I}^{2}=70 \%$ when assessing 90-day functional independence. The study also demonstrated a relatively high rate of postprocedural symptomatic intracranial hemorrhage (8\%) and complications (11\%) in the elderly population. ${ }^{23}$ Because our work was retrospective it does not resolve this controversy, but it does add several valuable key points. First, we report on a large 
Table 5 Multivariate analysis for predictors of good outcome at 90 days after endovascular thrombectomy by TICl score

\begin{tabular}{|c|c|c|c|c|c|c|}
\hline \multirow[b]{2}{*}{ Variable } & \multicolumn{3}{|c|}{ Multivariate $-\mathrm{TICI} 2 \mathrm{~b}(\mathrm{n}=554)$} & \multicolumn{3}{|c|}{ Multivariate $-\mathrm{TICI} 2 \mathrm{c} / 3(\mathrm{n}=489)$} \\
\hline & OR & $95 \% \mathrm{Cl}$ & $P$ values & OR & $95 \% \mathrm{Cl}$ & $P$ values \\
\hline Female gender & 0.83 & 0.54 to 1.26 & 0.376 & 0.58 & 0.39 to 0.85 & 0.006 \\
\hline White & 0.89 & 0.56 to 1.4 & 0.604 & 1.25 & 0.83 to 1.88 & 0.280 \\
\hline Age $\geq 80$ & 0.43 & 0.25 to 0.74 & 0.002 & 0.43 & 0.27 to 0.69 & $<0.001$ \\
\hline Onset-to-groin time & 1.00 & 1 to 1 & 0.317 & 1.00 & 1 to 1 & 0.762 \\
\hline Pre-stroke mRS & 0.58 & 0.43 to 0.78 & $<0.001$ & 0.80 & 0.67 to 0.95 & 0.011 \\
\hline Baseline NIHSS & 0.88 & 0.85 to 0.91 & $<0.001$ & 0.91 & 0.88 to 0.93 & 0.000 \\
\hline Posterior circulation stroke & 0.57 & 0.29 to 1.12 & 0.101 & 0.40 & 0.2 to 0.79 & 0.009 \\
\hline Number of comorbidities & 0.95 & 0.8 to 1.13 & 0.553 & 0.92 & 0.79 to 1.09 & 0.349 \\
\hline IV tPA & 1.01 & 0.65 to 1.57 & 0.967 & 1.12 & 0.75 to 1.68 & 0.573 \\
\hline IA tPA & 0.89 & 0.49 to 1.61 & 0.700 & 1.09 & 0.65 to 1.84 & 0.736 \\
\hline Number of attempts & 0.90 & 0.78 to 1.04 & 0.160 & 0.85 & 0.75 to 0.95 & 0.005 \\
\hline Complications & 0.15 & 0.03 to 0.8 & 0.026 & 0.80 & 0.32 to 1.98 & 0.625 \\
\hline
\end{tabular}

Variables showing statistical significance $(p<0.05)$ are in bold.

mRS, modified Rankin Scale; NIHSS, National Institutes of Health Stroke Scale; TICl, Thrombolysis in Cerebral Infarction; tPA, tissue plasminogen activator.

dataset of 1346 patients undergoing ET at tertiary centers from geographically diverse regions in the USA, providing supporting evidence that octogenarians have higher rates of postprocedural hemorrhage, mortality, and poor outcomes than younger counterparts. Second, in contrast to studies that report that comorbidities and baseline deficits are responsible for the differences in outcomes between the young and elderly, our data suggest that the increased morbidity of ET in the elderly is independent of comorbidities, procedural variables, and baseline deficits. Thus, it is age that accounts for this disparity in outcomes. Third, our data suggest that the lower rates of functional independence in octogenarians are not explained by lower recanalization, the thrombectomy approach used, or the location of the stroke. In contrast, prior work has shown that successful recanalization resulted in higher odds of good outcomes in patients aged $\geq 70$

Table 6 Multivariate analysis for predictors of postprocedural hemorrhage after endovascular thrombectomy.

\begin{tabular}{|c|c|c|c|}
\hline \multirow[b]{2}{*}{ Variable } & \multicolumn{3}{|c|}{ Multivariate model - hemorrhage $(n=1226)$} \\
\hline & $\mathrm{OR}$ & $95 \% \mathrm{Cl}$ & $P$ values \\
\hline Female gender & 1.31 & 0.99 to 1.74 & 0.060 \\
\hline White & 1.07 & 0.8 to 1.44 & 0.630 \\
\hline Age $\geq 80$ & 1.59 & 1.13 to 2.24 & 0.008 \\
\hline Onset-to-groin time & 1.00 & 1 to 1 & 0.492 \\
\hline Pre-stroke mRS & 0.76 & 0.67 to 0.87 & $<0.001$ \\
\hline Baseline NIHSS & 1.04 & 1.02 to 1.07 & $<0.001$ \\
\hline Number of comorbidities & 1.04 & 0.92 to 1.17 & 0.513 \\
\hline Posterior circulation stroke & 0.56 & 0.34 to 0.9 & 0.018 \\
\hline Prior stroke & 1.00 & 0.6 to 1.66 & 0.992 \\
\hline IV tPA & 1.04 & 0.78 to 1.39 & 0.796 \\
\hline IA tPA & 0.95 & 0.65 to 1.39 & 0.787 \\
\hline Number of attempts & 1.05 & 0.98 to 1.14 & 0.179 \\
\hline $\mathrm{TICl}$ score & 1.16 & 1.03 to 1.3 & 0.013 \\
\hline Complications & 1.62 & 0.9 to 2.95 & 0.110 \\
\hline
\end{tabular}

Variables showing statistical significance $(p<0.05)$ are in bold.

mRS, modified Rankin Scale; NIHSS, National Institutes of Health Stroke Scale; TICI,

Thrombolysis in Cerebral Infarction; tPA, tissue plasminogen activator. years compared with younger counterparts. ${ }^{33}$ This effect was not seen in our data when we used multivariate analysis controlling for additional variables, including complications, onset-to-groin time, number of recanalization attempts, and location of stroke (anterior vs posterior).

Our findings and the accumulating literature on ET in octogenarians should be interpreted with caution. Rather than provide a blanket age cut-off point for exclusion of patients potentially eligible for thrombectomy, our data underscore the need to optimize the selection criteria for elderly patients undergoing ET. In this manner, the disparity between outcomes in the two age groups could be minimized. There is no validated selection paradigm for ET in the elderly, and the real-world practice of liberal inclusion of elderly patients as candidates for ET based on criteria applicable to younger counterparts should be re-examined.

Previous studies have suggested the use of pre-stroke mRS score at baseline as a selection criterion ${ }^{23}$; however, in our work the low rates of functional independence in elderly people were not explained by baseline mRS score, and age $\geq 80$ years was an independent predictor of outcomes even when controlling for pre-stroke deficits. Also, it is worth noting that in the present dataset more than $90 \%$ of patients in both age groups had a baseline $\mathrm{mRS}$ of between 0 and 1, indicating that this selection criterion is already applied by providers. In addition, elderly patients were taken for thrombectomy with smaller core infarcts (higher ASPECTS), suggesting again that some mild degree of closer scrutiny was applied to the elderly patients in this dataset, although in a non-standardized fashion.

Therefore, future emphasis should be on using data from the current literature to test different selection algorithms based on baseline, demographic, and procedural data to determine patient eligibility for ET, and optimize selection. For this, retrospective data and large repositories are of specific importance. These datasets may not provide level 1 evidence for implementation but do provide an appropriate resource to test an optimal selection strategy to be used in future prospective studies. With the expansion of indications for ET, the design of an RCT to evaluate the different settings of potential ET usefulness may not be feasible or cost-effective. Despite these data, conclusive evidence is still required from RCTs, but data from large multicenter repositories are highly significant since they allow for optimal 
Ischemic Stroke

Table 7 Multivariate analysis for predictors of good outcome at 90 days after endovascular thrombectomy by age group

\begin{tabular}{|c|c|c|c|c|c|c|}
\hline \multirow[b]{2}{*}{ Variable } & \multicolumn{3}{|c|}{ Multivariate model ( $<80$ years) $(n=879)$} & \multicolumn{3}{|c|}{ Multivariate model ( $\geq 80$ years) $(n=301)$} \\
\hline & OR & $95 \% \mathrm{Cl}$ & $P$ values & OR & $95 \% \mathrm{Cl}$ & $P$ values \\
\hline Female gender & 0.64 & 0.47 to 0.87 & 0.004 & 0.72 & 0.37 to 1.4 & 0.337 \\
\hline White & 0.96 & 0.69 to 1.32 & 0.788 & 0.92 & 0.42 to 2 & 0.834 \\
\hline Onset to groin time & 1.00 & 1 to 1 & 0.178 & 1.00 & 1 to 1 & 0.420 \\
\hline Pre-stroke mRS & 0.78 & 0.66 to 0.92 & 0.003 & 0.66 & 0.48 to 0.9 & 0.010 \\
\hline Baseline NIHSS & 0.90 & 0.88 to 0.92 & $<0.001$ & 0.88 & 0.83 to 0.92 & $<0.001$ \\
\hline Number of comorbidities & 0.88 & 0.78 to 1 & 0.055 & 1.32 & 0.99 to 1.75 & 0.057 \\
\hline Posterior circulation stroke & 0.35 & 0.21 to 0.57 & $<0.001$ & 3.43 & 1.09 to 10.78 & 0.035 \\
\hline Prior stroke & 1.03 & 0.55 to 1.94 & 0.924 & 1.13 & 0.36 to 3.59 & 0.834 \\
\hline IV tPA & 1.09 & 0.79 to 1.5 & 0.604 & 1.27 & 0.62 to 2.57 & 0.513 \\
\hline IA tPA & 0.89 & 0.59 to 1.35 & 0.594 & 0.88 & 0.35 to 2.2 & 0.792 \\
\hline Number of attempts & 0.87 & 0.79 to 0.96 & 0.005 & 0.68 & 0.53 to 0.87 & 0.003 \\
\hline Use of aspiration at first pass & 0.91 & 0.64 to 1.27 & 0.568 & 0.95 & 0.47 to 1.93 & 0.891 \\
\hline $\mathrm{TICl}$ score & 1.28 & 1.12 to 1.47 & $<0.001$ & 1.22 & 0.9 to 1.64 & 0.204 \\
\hline Complications & 0.48 & 0.22 to 1.04 & 0.063 & 0.39 & 0.06 to 2.42 & 0.310 \\
\hline
\end{tabular}

Variables showing statistical significance $(\mathrm{p}<0.05)$ are in bold.

mRS, modified Rankin Scale; NIHSS, National Institutes of Health Stroke Scale; TICl, Thrombolysis in Cerebral Infarction; tPA, tissue plasminogen activator.

design of RCTs and reflect real-world practice, especially when selectively choosing patients cannot be easily implemented.

Several new observations are reported in our work. We show that a higher TICI score is associated with increased odds of functional independence in younger but not elderly population. These data suggest the need for careful attention to expected outcomes and endpoints when the decision to perform ET in octogenarians is made. Although perfection of angiographic outcomes by progression of reperfusion attempts to achieve complete revascularization in the young is justified, this may not be the case in the elderly, where discretion is needed when considering acceptable intraprocedural outcomes. ${ }^{34}$ In general, a post-thrombectomy TICI $2 \mathrm{~b}$ result may be more acceptable in the elderly even if further attempts to achieve TICI 3 may have been used in younger counterparts.

In addition, an important observation of this work is that posterior circulation strokes were associated with poorer outcomes in the young adults but with better outcomes in the elderly patients (table 7). This needs further investigation, but a likely explanation in this retrospective dataset is selection bias for ET, with exclusion of elderly patients with the less favorable posterior circulation strokes and broader inclusion of prognostically worse posterior strokes in the younger population.

We also evaluated the difference in immediate benefit of ET between groups and found that the change in NIHSS score between admission and postprocedure was significantly lower in the elderly than in younger adults. The similarity in length of hospitalization post-thrombectomy between groups suggests this difference in change of the NIHSS score is probably not due to non-procedural complications. A possible explanation is that elderly patients as a group have lower baseline neuronal reserve, capacity for remodeling, and plasticity, limiting their potential for improvement post-thrombectomy.

\section{Limitations}

The retrospective nature of the study is one of the limitations of this work; however, observations from large multicenter retrospective studies provide essential guidelines for the design and implementation of meaningful future RCTs. Another limitation is that the data presented here are from unique high-volume comprehensive stroke centers using a variety of currently accepted selection and technical strategies for ET, including a combination of aspiration and stent retriever thrombectomy; however, we performed subgroup analysis for each technique independently to establish the robustness of the findings. Finally, the observation that length of stay did not differ between the groups (elderly vs young) should be interpreted with caution owing to the significantly higher mortality, including in-hospital mortality, in the elderly.

\section{CONCLUSION}

This large, geographically diverse multicenter experience of patients treated for emergent large vessel occlusion with both direct aspiration and stent retriever thrombectomy has demonstrated that outcomes among the elderly ( $\geq 80$ years) are inferior. This outcome disparity is apparent despite evidence suggesting a non-standardized degree of 'hyperselection' of the elderly, as reflected in higher rates of low baseline mRS score and higher ASPECTS (smaller core infarcts) at presentation, a phenomenon that may reflect practitioners more stringent selection criteria for elderly patients. Given the US healthcare system's emphasis on cost-effectiveness and value-based care with an increasingly ageing population further emphasizing these systems of care, our findings underline the need for further refinement and optimization of selection criteria for elderly patients being considered for thrombectomy.

\section{Author affiliations}

${ }^{1}$ Department of Neurosurgery, Medical University of South Carolina, Charleston, South Carolina, USA

${ }^{2}$ Department of Neurological Surgery and Neuroradiology, University of Miami, Miami, Florida, USA

${ }^{3}$ Department of Radiology and Radiological Sciences, Medical University of South Carolina, Charleston, South Carolina, USA

${ }^{4}$ Department of Neurosurgery, Mount Sinai Health System, New York City, New York, USA

${ }^{5}$ Radiology, Neurology \& Neurosurgery, West Virginia University, Morgantown, West Virginia, USA

${ }^{6}$ Neurological Surgery, Wake Forest University, Winston-Salem, North Carolina, USA ${ }^{7}$ Department of Neurosurgery, Baylor College of Medicine, Houston, Texas, USA 
${ }^{8}$ Department of Neurology, Baylor College of Medicine, Houston, Texas, USA

${ }^{9}$ Department of Neurosurgery, University of Arizona, Tucson, Arizona, USA

Correction notice Since this paper was first published online the author Fábio Nascimento has been updated to Fábio A Nascimento.

Contributors Each author listed should receive authorship credit based on the material contribution to this article, their revision of this article and their final approval of this article for submission.

Funding The authors have not declared a specific grant for this research from any funding agency in the public, commercial or not-for-profit sectors.

Competing interests AT: consulting-Codman, Penumbra, Microvention, Blockade, Pulsar Vascular, Medtronic, Siemens; research grants- Codman, Penumbra, Microvention, Pulsar Vascular, Medtronic; Stock- Pulsar Vascular, Blockade. PKconsultant, Medtronic and Stryker neurovascular. AMS: consulting- Penumbra, Pulsar Vascular, Microvention, Stryker; honorarium- Penumbra, Pulsar Vascular, Microvention, Stryker; speaker bureau- Penumbra, Pulsar Vascular, Microvention Stryker; research- Microvention.

Patient consent Not required.

Ethics approval MUSC IRB.

Provenance and peer review Not commissioned; externally peer reviewed.

\section{REFERENCES}

1 Balami JS, Sutherland BA, Edmunds LD, et al. A systematic review and meta-analysis of randomized controlled trials of endovascular thrombectomy compared with best medical treatment for acute ischemic stroke. Int I Stroke 2015;10:1168-78.

2 Berkhemer OA, Fransen PS, Beumer D, et al. A randomized trial of intraarterial treatment for acute ischemic stroke. N Engl I Med 2015;372:11-20.

3 Campbell BC, Mitchell PJ, Kleinig TJ, et al. Endovascular therapy for ischemic stroke with perfusion-imaging selection. N Engl I Med 2015;372:1009-18.

4 Goyal M, Demchuk AM, Menon BK, et al. Randomized assessment of rapid endovascular treatment of ischemic stroke. N Engl J Med 2015;372:1019-30.

5 Jovin TG, Chamorro A, Cobo E, et al. Thrombectomy within 8 hours after symptom onset in ischemic stroke. N Engl I Med 2015;372:2296-306.

6 Saver JL, Goyal M, Bonafe A, et al. Stent-retriever thrombectomy after intravenous t-PA vs. t-PA alone in stroke. N Engl J Med 2015;372:2285-95.

7 Desai SM, Rocha M, Molyneaux BJ, et al. Thrombectomy 6-24 hours after stroke in trial ineligible patients. J Neurointerv Surg 2018

8 Fugate JE, Brinjikji W, Cloft H, et al. Variability of stroke patients meeting endovascular stroke trial criteria in a non-clinical trial setting. J Neuroradiol 2018:45:192-5.

9 Alawieh A, Chatterjee A, Feng W, et al. Thrombectomy for acute ischemic stroke in the elderly: a 'real world' experience. J Neurointerv Surg 2018. doi: 10.1136/ neurintsurg-2018-013787 [Epub ahead of print].

10 Loh Y, Kim D, Shi ZS, et al. Higher rates of mortality but not morbidity follow intracranial mechanical thrombectomy in the elderly. AJNR Am J Neuroradiol 2010:31:1181-5.

11 Mishra NK, Ahmed N, Andersen G, et al. Thrombolysis in very elderly people: controlled comparison of SITS International Stroke Thrombolysis Registry and Virtual International Stroke Trials Archive. BMJ 2010;341:c6046.

12 Chandra RV, Leslie-Mazwi TM, Oh DC, et al. Elderly patients are at higher risk for poor outcomes after intra-arterial therapy. Stroke 2012;43:2356-61.

13 To CY, Rajamand S, Mehra R, et al. Outcome of mechanical thrombectomy in the very elderly for the treatment of acute ischemic stroke: the real world experience. Acta Radiol Open 2015;4:2058460115599423.

14 Kuntze Söderqvist Å, Andersson T, Wahlgren N, et al. Mechanical thrombectomy in acute ischemic stroke-patients with wake-up stroke and the elderly may benefit as well. J Stroke Cerebrovasc Dis 2016;25:2276-83.
15 Alawieh A, Vargas J, Turner RD, et al. Equivalent favorable outcomes possible after thrombectomy for posterior circulation large vessel occlusion compared with the anterior circulation: the MUSC experience. J Neurointerv Surg 2018;10:735-40.

16 Haussen DC, Bouslama M, Grossberg JA, et al. Too good to intervene? Thrombectomy for large vessel occlusion strokes with minimal symptoms: an intention-to-treat analysis. J Neurointerv Surg 2017;9:917-21.

17 Jayaraman MV, McTaggart RA. Endovascular treatment of anterior circulation large vessel occlusion in the elderly. Front Neurol 2017:8:713.

18 Kim DH, Kim SU, Sung JH, et al. Significances and outcomes of mechanical thrombectomy for acute infarction in very elderly patients: a single center experience. $J$ Korean Neurosurg Soc 2017;60:654

19 Pfaff J, Pham M, Herweh C, et al. Clinical outcome after mechanical thrombectomy in non-elderly patients with acute ischemic stroke in the anterior circulation: primary admission versus patients referred from remote hospitals. Clin Neuroradiol 2017:27:185-92.

20 Son S, Kang DH, Hwang YH, et al. Efficacy, safety, and clinical outcome of modern mechanical thrombectomy in elderly patients with acute ischemic stroke. Acta Neurochir 2017;159:1663-9.

21 Vargas J, Spiotta AM, Fargen K, et al. Experience with A Direct Aspiration First Pass Technique (ADAPT) for thrombectomy in distal cerebral artery occlusions causing acute ischemic stroke. World Neurosurg 2017;99:31-6.

22 Mourand I, Abergel E, Mantilla D, et al. Favorable revascularization therapy in patients with ASPECTS $\leq 5$ on DWI in anterior circulation stroke. J Neurointerv Surg 2018;10:5-9.

23 Hilditch CA, Nicholson P, Murad MH, et al. Endovascular management of acute stroke in the elderly: a systematic review and meta-analysis. AJNR Am J Neuroradiol 2018;39:887-91

24 Imahori T, Tanaka K, Arai A, et al. Mechanical thrombectomy for acute ischemic stroke patients aged 80 years or older. J Stroke Cerebrovasc Dis 2017;26:2793-9.

25 Hirsch JA, Mehta BP, Chandra RV, et al. Efficacy of IAT in elderly requires further study. J Neurointerv Surg 2016;8:e6-7.

26 Hacke W, Kaste M, Fieschi C, et al. Randomised double-blind placebo-controlled trial of thrombolytic therapy with intravenous alteplase in acute ischaemic stroke (ECASS II). Second European-Australasian Acute Stroke Study Investigators. Lancet 1998:352:1245-51.

27 Almekhlafi MA, Davalos A, Bonafe A, et al. Impact of age and baseline NIHSS scores on clinical outcomes in the mechanical thrombectomy using solitaire FR in acute ischemic stroke study. AJNR Am J Neuroradiol 2014;35:1337-40.

28 Flint AC, Cullen SP, Faigeles BS, et al. Predicting long-term outcome after endovascular stroke treatment: the totaled health risks in vascular events score. AJNR Am J Neuroradiol 2010;31:1192-6.

29 Goyal M, Menon BK, van Zwam WH, et al. Endovascular thrombectomy after large-vessel ischaemic stroke: a meta-analysis of individual patient data from five randomised trials. Lancet 2016:387:1723-31.

30 Alawieh A, Pierce AK, Vargas J, et al. The golden 35 min of stroke intervention with ADAPT: effect of thrombectomy procedural time in acute ischemic stroke on outcome. J Neurointerv Surg 2018;10:213-20.

31 Duffis EJ, He W, Prestigiacomo CJ, et al. Endovascular treatment for acute ischemic stroke in octogenarians compared with younger patients: a meta-analysis. Int I Stroke 2014:9:308-12.

32 Singer $\mathrm{OC}$, Haring HP, Trenkler J, et al. Age dependency of successful recanalization in anterior circulation stroke: the ENDOSTROKE study. Cerebrovasc Dis 2013:36(56):437-45.

33 Slater LA, Coutinho JM, Gralla J, et al. TICl and age: what's the score? AJNR Am J Neuroradiol 2016:37:838-43.

34 Spiotta AM, Arthur AS, Fiorella D, et al. Is discretion the better part of valor? $J$ Neurointerv Surg 2018. 